\title{
The Use of Thumbnail Sketches in Visual Arts Education: Exploring High School Students' Perspective in the Design Process
}

\author{
Patience Vanderpuye $^{1} \quad$ Edward Appiah $^{2} \quad$ Albert Boamah $^{3 *}$ \\ 1.Takoradi Technical University, P.O Box 256, Takoradi, Western Region-Ghana \\ 2.Kwame Nkrumah University of Science and Technology, Private Mail Bag, University Post Office, Kumasi- \\ Ghana \\ 3.University of Education, Winneba, Post Office Box 25, Winneba-Ghana
}

\begin{abstract}
The study explored the understanding of SHS students on thumbnail sketches as a key tool in the design process. The study utilized the qualitative research approaches using observation and informal interviews to solicit for data. The activity theory was adopted to engage students in the activity of thumbnail sketching. The study revealed the positive mindset of some students to the acknowledgment of thumbnail sketches as ways of generating ideas. The study also revealed negative attitudes of students towards thumbnail sketching activities when undertaking a design activity. The idea of performing thumbnail sketches using both technological and the traditional methods is recommended as effective ways of achieving insightful ideas for effective designing.
\end{abstract}

Keywords: Thumbnail sketches, Graphic design education, idea development, design process.

DOI: $10.7176 / \mathrm{ADS} / 88-03$

Publication date: December $31^{\text {st }} 2020$

\section{Introduction}

Thumbnail sketches, as a tool in the graphic design process plays enormous role in design education. This role varies from project to projects, especially when it is used as a means or instrument to communicate ideas, for refining of visual solution and exploration, and as a reference or educative material. According to Hodge (2008), thumbnail sketching has proven to be the fastest way of visual communication or representation, for Graphic designers and other designers in other disciplines.

Graphic design is a visual problem-solving activity that calls for brainstorming to produce better communication solution. This is where thumbnail sketching is considered a key tool in the Design Process. Thumbnail sketches, which are part of the brainstorming process, are quick sketches or drawings of ideas which help the designer brainstorm for multiplicity of ideas (Kusuma et al., 2017). The idea of thumbnail sketching involves several ideas in the form of thumbnails on paper or relevant substrate and choosing the most appropriate for the final design. A thumbnail sketch is used to serve as reference, inspiration and as educational material and an important tool in the design process.

As part of the aims of the curriculum for graphic design education at the Senior High School (SHS) level in Ghana, students are expected to develop effective manipulative skills using tools and material and to acquire perceptual and analytical skills through direct artistic experience and through the process of self- expressions (CRDD, 2007). However, studies have revealed that Ghanaian graphic design students are changing the way they undertake their design processes as far as thumbnail sketches are concerned. This is reported in the studies of Appiah \& Cronje (2012) and Jona (2012) which revealed that design students do thumbnail sketches after their design work and others do not engage in it at all, whereas, the ideal sense of thumbnail sketches are to be done before the main design and through which creative idea or concept should be chosen for the design work (Hodge, 2008).

For decades now, there has been the introduction of internet and other computer packaged programmes for graphic design education. Studies have revealed that there has been changes in students' design work that no longer appear teacher expectations. Investigations the studies of Appiah and Cronje (2012) and Jona (2012) have also brought to light that students no longer use thumbnail sketches to generate ideas from which a final concept is selected for final development of the design concept but rather the other way around. These have been attributed to the introduction of computers and sophisticated computer designed programmes for graphic design education (Jona, 2012).

According to Johnson, Tan and Melles (2010), the design process commences with thumbnail sketches which assist the designer to brainstorm for creative ideas. Yet, the Ghanaian Graphic design student seems to have problems with thumbnails sketching as part of the design process (Appiah and Cronje, 2012; Alu, 2011; Lartey, 2009; Jona, 2012) and many others. A study by Appiah and Cronje (2012) discovered that design students in the higher educational institutions no longer produce design works to tutor expectations of the design process. Even though students are mandated to submit thumbnail sketches of their ideas and solution for the 
design problem on paper, out of which a final layout or composition will be chosen for their finished design pieces, it was realized students hardly adhere to these practices. A study by Johnna (2012) on the effects of computer on graphic design education in four Senior High Schools in the Central Region of Ghana, also revealed that student expresses that they feel lazy to sketch their ideas on paper before choosing the most appropriate for their final design. Most students import images and objects from the internet and these are chosen for their works. This is a form of deviation in students' ability to strictly follow the design process in connection with thumbnail sketches. Therefore, Appiah and Cronje (2012), Alu (2011), Lartey (2009), Jona (2012) and other researchers are of the opinion that if emphasis will be laid on practicing thumbnail sketching, especially at the SHS level in Ghana, it will help alleviate some of the problems associated with higher institutional levels of graphic design education.

This study explores the understanding of SHS students in relation to thumbnail sketches as a key tool in the graphic design process. It goes further to explore students' perception on the concept of thumbnail sketching in the graphic design process as a universal tool and specifically in relation to design education. This is important as the findings of the inquiry would be valuable to both graphic design students and educators, specifically for teaching idea development in the design process.

\section{Literature Review}

\subsection{The Role of Thumbnail Sketches in Graphic Design Process and Education at the SHS Level}

Thumbnail sketches as a tool in the graphic design process plays variety of roles according to the aim of the designer or the end product of the design. These include size, choice, style, designers' capability and clients' expectancy are all contributing factors. Thumbnail sketches in a design project saves enormous time and helps manage budgets. This ensures that, huge amount of money and time is invested only in refined solutions, with sketches, the designer begins work only upon an agreement with the client and approval. Sketching can begin with basic concepts and then move on to a more refined composition and then on to a more refined detailed sketching for the final design. Due to the above mentioned, some researchers believe that, there is no scarcity of software, hardware or traditional tools for producing marvellous designs (Appiah \& Cronje, 2012; Hodge, 2008; Jona, 2012). It seems that whatever a designer imagine, software and hardware can make it materialize, and adding thumbnail sketches to a design process is a great way to amplify the tools and ideas for designing. Thumbnail sketches provide a unique space that helps designers think differently and generate a variety of ideas.

Designers, especially beginners therefore must note that it is advisable to begin idea development on paper than the computer. Furthermore, James, a bicycle designer, in his article, "introduction to graphic design" expressed how putting ideas on paper is the only way to evaluate them to see if they are worth exploring (Hodge, 2008). He further explained that, computer renderings and modern computer aided design packages are great, but thinking on paper with a pencil is always the fastest and the best way to explore ideas.

In the senior high schools, where logo design and illustration processes are the basic and major components of the graphic design syllabus, thumbnail sketches are very useful as well, as there is no need for drawing skills to work out compositions. The more thumbnail sketches a designer does, the more he improves upon the final design (Kusuma et al., 2017).

A research on the effect of computer in teaching graphics students in eight selected senior high schools in the central region by Jona (2012) unveiled that designing with the computer helps the students improve the creativeness of their works, enhances teaching and learning, sharpens students' skills and equips them for effective design works. It serves as an aid and future reference, extending working speed in terms of the design process. However; the researcher, Jona (2012) findings showed that, the computer aided designs had a negative effect on students' creativity, in the sense that most students felt lazy to start their designs with thumbnail sketches, instead, students were importing images direct from the internet for their works without taking time to understand the images they import.

Hodge (2008) believes that the use of computer in teaching graphic design should go hand in hand with the manual rendering so that students will acquire both skills in order to be versatile and be confident to compete on the job market rather than to be well-equipped in the computer usage and be deficient in the manual rendering. The acquisition of both skills will enhance their skills in designing. Practicing and using thumbnail sketches makes both learners and practitioners more familiar with design tools and materials at hand and makes them happy and enjoys sketching.

The studies of Appiah and Cronje (2012) and Jona (2012) therefore expound to the understanding of learners and educators that there is no better approach for exploring multiple visual solution than sketching. A hand-drawn sketch or manual rendering plays an important role in the graphic design process including digital arts. The larger the project the more concepts a client's desire to see related sketches before quick approval

\subsection{Theoretical Framework}

The theory engaged in this study is the activity theory, which is a theoretical framework for analyzing and 
understanding of human interaction by the use of tools. The theory also proposes a complete and appropriate approach for discovery that can be applied in supporting a qualitative and interpretive research such as this study, as expounded by Hasan and Alana (2014) in their study. The theory can be traced to the works of the Russian psychologists Vygotsky and Leontiev in the 1920s. The activity theory originates from the socio-cultural tradition in the Russian psychology, where it offers better understanding to human activities (Hasan and Kazlauskas, 2014). The main objective of the activity theory is to understand human activities in social settings. The activity theory is chosen based on the objectives and the purpose of this study and also in (accordance with) consideration of inculcating traditional thumbnail sketches as a tool in Graphic design, as recommended by Appiah \& Cronje (2012) and Jona (2012).

Generally, activity theory is involved in engaging some activity-oriented work or being actively engaged in some work. It is also about who is doing what, why the person is doing what he or she is doing and how the person is doing what he or she is doing (Hasan \& Kalauskas, 2014). This can be explained as an interaction between a person, which is also referred to as the subject by the activity theory, and the world in which he/she live in.

The activity theory is of much relevance to this study hence it is a socio-cognitive theory that takes into much consideration the subject and the object though there are other components as well. This theory is more interested in human activity in a specific social setting such as learning. It would be useful in analyzing the activities of graphic design students in connection with thumbnail sketching as an important tool in the graphic design process as used by Tan and Melles (2010) in their study (graphic designers' tool-mediated activity during the conceptual design phase) as they explained how the activity theory helped them to understand how designers uses their tools and also to analyse their actions as well.

\section{Methodology}

A qualitative approach was adopted for this study. The qualitative method is explained by Denzin \& Lincoln (2005) and Creswell (2003) to be involved and interpretive to the naturalistic world. This means that qualitative researchers study things in their natural settings attempting to make sense of or interpret in terms of the meanings people bring to them. The population of the study were Visual Art students of Senior high schools with the sample drawn from KNUST Senior High School and St. Louis Senior High School, all within the Kumasi Metropolis, Ashanti Region. These schools were selected using the convenience sampling technique. Data was collected from participants using observation and informal interview with open-ended questions. With this method both participants were at liberty to express themselves and to provide their own answers to the questions posed at their own pace (Creswell, 2006). The data collection activity took place in the Visual arts classrooms (of the sampled Senior High Schools) during an active class session with students undertaking the topic thumbnail sketches. The study employed the thematic data analysis approach in analyzing the qualitative data collected through observation and unstructured interview. Thematic data analysis is explained by Thomas \& Harden (2008) to involve a line-by-line labelling of field note and transcribing data gathered from interview and field notes from observation, in the development of interpretive themes that corresponds with the objective of the study. Few sketches and images were also analysed where applicable.

Data gathering was guided by ethical consideration hence permission was sought from the securities, heads of departments, heads of sections, class teachers and all participants as related to Creswell (2005) illustration of how unethical it is to enter an organization or social setting to collect data without permission from the 'gatekeepers' of the organization. Therefore, access was an important key to attain the required information. Respondents (students) were also assured of their privacy in the information giving out as it is the responsibility of the researcher to protect the participants of the study in terms of ethical issues. This is in order that the data obtained and representation will be balanced. Participants (students) were well informed and their permission sought ahead of time or before the beginning of the study.

\section{Data Presentation and Analysis}

\subsection{Data from Observation and Interview During the Activity of Thumbnail Sketching}

The themes from the observation that emerged from the observation protocol were developed in relation with the activity theory, which was the framework used as the lens for the study, and from which the research questions of the study were drawn. These themes were therefore focused on answering the research questions, as captured in relation to the subjects within activity theory. Data that were captured but did not fall under any category of the subjects in the activity were represented in the protocol as field notes, in order to draw valid conclusion from the study.

The key focus in the observation was to analyse the extent to which these students understand thumbnail sketching in the design process. From the observation, it was noted in the first session of the class that the teacher emphasised on the importance of how students had to go through the graphic design process in order to generate ideas for their designs. According to the instructions, this has to be done with particular reference to the 
steps and processes of generating ideas through the sketching of a series of thumbnails. This was meant to aid in coming up with very good concepts full of ideas for the final designs.

In the second class session of the activity, the idea of generating thumbnail sketches was emphasized by the teacher as a call to developing numerous ideas for the design of logos. He justifies the use of thumbnail sketches as a very important step in the graphic design process that should not be skipped. Students were introduced to the concept of designing (logo) by, first, recognizing the need and the purpose of the design. According to the teacher, such recognition of the purpose the design is intended to serve and aid the students in coming up with a series of ideas and layout of the final design.

In this session, students were led to a clear concept in communication design technology and the different forms of media for communication design. Significantly, in this session, logo was used as an example to explain further the design process; from thumbnails, roughs, final roughs, to finished rough. It was also observed that the teacher had to task, participants (students) to develop thumbnail sketches of their own ideas for the final designs of the WASSCE project. According to the teacher, this was in order to examine the students' understanding of the practical aspect of graphic design. A series of sketches of ideas were derived by students as ordered by the teacher. From observation, some of the contents generated were appropriate for the activity understudy whiles others appeared inappropriate. Other contents also related to each other while others have nothing in common. Emphasis was also laid on the traditional method of sketching with pencil on the sketchbooks as far as the tools used. Students paid rapt attention and focused on the task of generating thumbnail sketches of their ideas for the final design of their project. Five sketchbooks were randomly selected as samples of each session. The sketches analysed were of the same projects from the two sessions. Therefore, teacher requirement or expectations of outcome for both sessions were almost similar in detail as far as the steps of processes are concerned. The sketches of the selected samples were closely observed.

Themes developed from the observation and interview protocols includes;

i. $\quad$ Students' Attitude Towards the use of Thumbnail Sketches

ii. $\quad$ Understanding Thumbnail Sketching

iii. $\quad$ Traditional versus Technology

\subsection{Students' Attitude Towards the Use of Thumbnail Sketches}

In order to examine the understanding of students in the SHS on thumbnail sketches, it was very necessary to establish students' attitude towards the use of thumbnail sketches in the activity of idea development in the graphic design process.

Findings from the observation session indicated that, the majority of the participants reacted reluctantly towards the generation of thumbnail sketches, especially with pencil on paper. Other students also engaged in sketching, under duress. This stems from their attitude during class sessions where they can be seen sitting idle, gazing into the ceiling and the window as if the ideas will be coming down from the sky or outside. Only a few participants carried out the activity enthusiastically, by going on to do the sketches as was ordered by the teacher. The willingness of this few participants drew the attention of the researchers to compare their developed ideas to other participants. The researchers notice that, the few participants who were very delighted about the activity came up with very good and explicit ideas for their final designs.

It was observed that the ideas developed by students from both class sessions relate to each other. They are appropriate and do not lack fluency. It was also recorded that during the interview session, it was these same students' who said they have their private or personal sketchbooks where they do thumbnail sketches during their leisure hours, and employs the sketches in their assignments. After the activity of the thumbnail sketches, researchers' sort to enquire from students if they enjoyed the activity, and the idea of thumbnail sketching before doing the actual design. Students A expressed their delight in undertaking thumbnail sketches. They further expressed that sketching is the only way they could use in generating ideas for their design works. This indicates that, only a few students are willing to do thumbnail sketches without being pushed about and will not do it to impress the teacher or just to fulfil academic demands or for formality sake (Appiah \& Cronje, 2012).

This finding supports the idea that, design students in general, understands the importance and the use of thumbnail sketches in the graphic design process. From all indications, students understand the importance and the use of thumbnail sketches in the graphic design process, but only a few students are willing to go through thumbnail sketching before moving on to the main design with their best ideas for the final design as recommended by Appiah and Cronje (2012), in their study on the higher educational graphic design students.

Another significant finding was the idea that majority of the students displayed an unwillingness towards the activity of thumbnail sketching in the graphic design process. Most of these students had much difficulty in registering their ideas on the paper during the first ten to fifteen minutes of the activity. Such situation created a lack of willingness to engage in thumbnail activities and when students finally engage in the activity, it was realised that the ideas being generated lack correlation with the final work. In those instances, one can realise that students take much time to do their final design before coming back to do their required thumbnail sketches 
for academic requirements. This indicates that, students understand the importance of thumbnail sketching in the graphic design process, but feel lazy and see it as a waste of time in doing thumbnail sketching. They only do it to fulfil academic requirement or teacher's expectations and will not follow instructions accordingly. Which also implies that, such students will graduate into the higher educational level with this same attitude towards sketching.

A respondent shared that,

and further elaborated that;

"I do thumbnails for marks",

"the idea development must be done and presented for marks".

Another respondent a jovial manner revealed by saying:

"our teacher likes thumbnail sketches so when I sketch more ideas, he will give me more marks".

Findings indicated lack of motivation of students to engage in thumbnail sketches and will do so in order to be awarded marks by the teacher at the end of the activity. This also confirms the findings of Appiah and Cronje (2012) in their study of the Higher Educational Graphic design that students will do thumbnail sketches after they have finished designing their masterpiece just to fulfil pedagogical demands of lecturers.

Some of the students do thumbnails only when it is an order from the teacher. According to them, whether they do thumbnails or not, they can still come up with their best, contending that the final outcome of their design no matter how good it is, look better than other colleagues' final designs. For these categories of students, thumbnail sketching and idea development is not an important tool in the graphic design process. Their perception context with who expressed similar challenges during his early design career until he started sketching. Such students who do not bother whether they do thumbnails or not, really needs to be made to understand the importance of thumbnail sketches in the graphic design process as elaborated by Hodge (2008). admonished teachers to immediately evaluate students' final works immediately the final work is executed, since that will help the students to understand that thumbnails are the pathway to creativity and solving design problems. Through that student will also understand how thumbnail sketching can take their designing skill to the next level.

Findings also reveal some category of students who were really sketching with real speed. These participants did the sketches with no proper arrangement and there were no grids to guide the positioning of the sketches. Responds upon researchers' enquiry of the speed indicated that, students were in a hurry to finish thumbnail sketches in order to be able to accomplish the final design. According to some of them;

the idea development fetches just small marks, but the real works

are what carries the major marks so I have to take much time in doing the main work'.

This gives indication that students are only interested in gaining the marks for academic reason and nothing else.

\subsection{Understanding Thumbnail Sketching}

During the observation of the activity of thumbnail sketching by students, it was realised that no student asked the teacher a question during the class sessions. Rather, students were seen interacting among themselves, with some of the students not giving the teacher their full attention whiles teacher was still explaining the lesson. This can imply that, students' perception towards the step of thumbnail sketching in the graphic design process makes them develop a negative attitude towards the activity of thumbnail sketching is as a result of students not paying much attention in class.

Results from the interview indicated that almost all respondents are familiar with the activity of thumbnail sketching and also known thumbnail sketching as an important step and a key tool in the graphic design process. For example, when asked about students' understanding of thumbnail sketching in the graphic design process one of the respondents indicated with the following;

"to me, thumbnail sketches are like the foundation for better designs,

it helps me generate more ideas for my design, so I do my design without difficulty because I do all planning and necessary corrections during the thumbnail sketching process".

Another respondent also said,

$$
\begin{aligned}
& \text { "the thumbnail sketches always help me come out with better ideas } \\
& \text { and designs" }
\end{aligned}
$$

In trying to know whether respondents see thumbnail sketches as a waste of time, it was interesting to realise that students do not see sketching thumbnails as a waste of time. As two respondents gave their views as;

"I don't see thumbnail sketching as a waste of time because it helps me come up with ideas that I never thought of, it gives me a very good concept for my design." 
"For me the more I sketch thumbnails, the better ideas I generate so it gives me the opportunity to choose from a variety of ideas. If there is any problem with my design, I see and correct it at the stage of thumbnail sketching before moving on to do my main design".

Ironically, students sometimes see thumbnails as an unnecessary waste of much of their contact hours or period so they do not get to finish their class works as a result of developing thumbnails. This, according to some participants, make the activity of thumbnail sketching very boring especially during class hours. For example, when a respondent was asked if he always does thumbnails prior to his main design, respondent said;

"nooooooo not always, I only do thumbnails when our teacher asks

us to do so, thumbnail sketching takes much of the contact hours with our teacher and so I don't get to finish my class work. And this makes the activity very boring",

Interestingly, while some students actually developed ideas for their design works through thumbnail sketching, as teachers always insist, others do not bother especially when the assignment is meant as a homework. On such occasions, they go on straight to do the actual work without resorting to any thumbnail activity. "A Respondent said,

"I do thumbnails when it is a class work and the teacher insist that I generate ideas before he approves my idea for the design. But if it's a homework, I don't bother myself with sketching of thumbnails, I go on straight to do my work so I can have time to do other things".

Significantly, students do agree that after the idea development process, they get better ideas for their final design. Respondent said,

$$
\begin{aligned}
& \text { "as for me thumbnail sketches because that's where I get my ideas } \\
& \text { for my designs, both homework and class work." }
\end{aligned}
$$

One interesting finding was the fact that few students owns both personal and academic sketchbooks where they try out some sketches during their leisure hours. These sketches do yield ideas and such ideas from the sketches are sometimes used for their assignments. Significantly, the researchers did not notice any student possessing more than one sketchbook during the active session of the activity aside the academic one. Surprisingly, one respondent said,

"the actual design is on my mind, whether I do thumbnails of the intended design or not, I can still come up with very good designs".

Another respondent who researchers noticed doing the final design before the idea development claimed

"I don't want to forget my intended designs so I have to sketch that one first".

One respondent who sketched the final design and kept it aside said,

"I already have a lot of the ideas in my mind, but this is the particular one I want to present as the final design. So, I have to sketch the desired or the preferred idea first".

When researchers sort to find out from participants, their reason or view on thumbnail sketching, the majority expressed that sketching thumbnails are helping them to develop ideas for their works. Some participants express that the ideas they sketch is their source of inspiration and also helps them solve design problems. This confirms the study of Sri which interpreted sources of inspiration as conscious uses of previous designs and other objects and images for pursuit of design, and the design problem lies in relation to what already exists. Critical decisions are made at the early stages of design, and the design ideas which are the soul of the final outcome is generated (Kusuma et al., 2017). These imply that, the SHS graphic design education is a preparation towards higher education where previous skill and generated ideas can be used to work out the great designs.

Some of the students said that, sketching plays a very significant role in the graphic design process because it helps them to produce more creative designs. This responds also indicates students' understanding on how sketching of thumbnails in the graphic design process leads to creativity and also rapid exploration of alternative ideas. These also indicates students understanding on how sketching supports the design process, being the designers' principal means of thinking and how it serves to direct, order, clarify and record ideas. (Kusuma et al., 2017).

\subsection{Traditional versus Technology}

In both sessions, the teachers placed emphasis on only the traditional way of thumbnail sketching or idea development. Traditional as an approach as used in this study describes the manual means of developing thumbnail sketching (pencil on paper) whereas technology describes the approach that utilizes technological equipment which aids and accelerates thumbnail sketch production. At a point in time the teachers taught on the 
disadvantages and advantages of using both the traditional thumbnail sketches in the design process. It can be realised that the teachers also made the students understand the importance of thumbnail sketches by directing them to use just the traditional tools to develop the thumbnail sketches. Perhaps, there were evidence of students not showing keen interest in the use of the traditional tools in previous exercises.

The tools employed in the generation of the traditional thumbnail sketches are very important in the graphic design process. As Hodge (2008) in his study expressed and further referred to designers, like Karley Barrett, the bio trekker logo designer who also supports the generation of the traditional thumbnails in the graphic design process.

Hodge (2008) went on further to mention James the bicycle designer, Bill and Sherrie, also designers, who used the same tools as students were observed using to explore their ideas for the final design. This confirms Hodge (2008), Tan \& Melles (2010) Appiah \& Cronje's (2012) statement that, the best way to begin is by designing the traditional method of pen/pencil on paper for thumbnail sketching, but not jumping straight onto the computer. Indeed, the available tools were mainly traditional tools comprising pencil, pen, sketchbooks, ruler, compass and eraser in sketching their ideas.

In answer to interview questions, some students also mentioned other tools like crayon, poster colours, marker pens and acrylic paints whiles only one student mentioned writing board as being part of the tools used in thumbnail generation during the idea development stage of the graphic design process. The students were aware of the traditional tools as well as other tools and methods of sketching in the graphic design process apart from the traditional way of sketching. Majority of the students mentioned the technological tools, with computers being the main tool, is an indication that, SHS graphic design students are not ignorant. They really know and understand the difference between traditional methods of thumbnail sketching and the technological way. They also have knowledge of what technological tools are.

During the observation of the thumbnail sketching activity, all participants used pencil on paper, (the traditional way of sketching). However, few participants expressed their desire to use other technological tools if allowed. Though no respondent mentioned Wacom tablet as being part of the technological tools.

When researchers enquired from participants which of the sketching methods they preferred, the majority of them said they have not had the opportunity to use the computer so they cannot tell which one is preferable over the other. They are only familiar with the traditional method of sketching. Only two students said they preferred using the computer because they have the skill and have been using the computer for their personal works. These two said they are comfortable with both methods of sketching.

\section{Conclusion}

In the quest to fill a gap in the existing literature in the area of thumbnail sketches as a key tool in the graphic design process at the SHS level of education, this study explored the understanding of SHS graphic design students' in connection with thumbnail sketches in the graphic design process. Furthermore, the study observed how teachers engage the SHS graphic design students in thumbnail sketching during the idea development stage of the graphic design process.

This study revealed Graphic design students' attitude towards thumbnail sketching which showed that they behave negatively towards the activity of thumbnail sketching in the graphic design process. Even though teachers try all possibilities to engage students in thumbnail sketching. It was also discovered that SHS graphic design students are reluctant and not fond of undertaking thumbnail sketching in the when doing a design work. This was confirmed by the way students responded that they have all their ideas in their mind. This is an indication that the desire, enthusiasm and perception of thumbnail sketching is subject to individual student. This should be a reason for design educators to impose the activity of thumbnail sketching on design students with the understanding that thumbnail sketches play enormous role in the graphic design process. Hence, this will prepare and shape SHS Graphic design students' minds towards the task ahead at the higher level of education in graphic design. The idea of performing thumbnail sketches using both the traditional and the technological methods should be encouraged to continually create the sustenance of the thumbnail sketching activity when performing design projects.

\section{References}

Alu, R. M. (2011). An investigation into the standard of drawing in selected Senior High Schools in Bekwai Municipality, Ashanti Region. Retrieved: May 3, 2020 from http://ir.knust.edu.gh/xmlui/handle/123456789/3984?show=full

Appiah, E., \& Cronje, J.C. (2012). Thumbnail sketches on idea development. The drawing board vs computer generation. Art, Design \& Communication in Higher Education, Intellect. 11(1) 49-61.

Engestrom, Y. (2000). Learning by expanding; an activity theoretical approach to developmental research', Orienta-Konsultit: Helsinki. 
Creswell, J.W. (2003). Research design: qualitative quantitative and mixed methods approaches. Thousand Oaks: Sage Publications.

Crewel, J.W. (2006). The selection of a research design. Thousand Oaks: Sage Publications.

Curriculum research and development division (CRDD). (2007). Teaching syllabus for graphic design - senior high schools, Accra, Ghana; Ministry of Education, Youth and Sports.

Denzin, N. K., \& Lincoln, Y. S. (2005). The SAGE handbook of qualitative research. Thousand Oaks: Sage Publications.

Hodge, S. (2008). The-role-of-sketching-in-the-design-process. Retrieved: May 3, 2020 from $\mathrm{http}$ //design.tutsplus.com/tutorials/the-role-of-sketching-in-the-design-process--psd-153. schools in Bekwai Municipality, Ashanti Region. Retrieved: May 14, 2020 from http://hdl.handle.net/123456789/3984.

Jona, E. (2012). The use of computer in teaching graphic design in selected high schools in the central region of Ghana. [Master's Thesis, Kwame Nkrumah University of Science and Technology]. Available: http://129.122.16.11/bitstream/123456789/7968/1/Emilia\%20Jonah.pdf

Lartey, T. A. (2009). Different strategies to fostering creativity in visual arts in senior high school. Master's Thesis, Kwame Nkrumah University of Science and Technology]. Available: http://ir.knust.edu.gh/bitstream/123456789/167/1/Binder1.pdf

Tan, S. and Melles, G. (2010). An activity theory focussed case study graphic designers "tool-mediated activities during the conceptual design phase. Retrieved: January 8, 2020 from http://linkinghub.Elsievier.com/retrieved/pii/so142694x10000426.

Vygotsky, L. (1978). Mind in society, the development of higher psychological processes. Cambridge: Cambridge University Press.

Hassan, H. \& Kaslauskas, A. (2014). Activity theory; who is doing what, why and why being practical with theory, a window into business research. Retrieved: May 18, 2020 from http://ro.uow.edu.au/buspaper/403

Kusuma, S. Daud, W.M., Mustaffa, F., Hanafizan, Hussain, H. (2017). Thumbnail sketches usage in organizing ideas for typography design. International journal of education and learning systems. (4)59-65. 